\title{
UJICOBA PENGEMBANGAN BUDIDAYA RUMPUT LAUT (Gelidium amansii) DENGAN METODE VERTIKAL LONGLINE
}

\author{
Oleh : \\ Gusti Aries dan lis Jubaedah \\ Dosen Jurusan Penyuluhan Perikanan Sekolah Tinggi Perikanan
}

\begin{abstract}
ABSTRAK
Rumput laut merupakan bahan baku bubur kertas (pulp) untuk pembuatan kertas. Jenis rumput laut yang dapat dijadikan bahan baku kertas adalah rumput laut yang mempunyai serat (fiber). Salah satu jenis rumput laut yang mempunyai serat tinggi dan baik adalah jenis Gelidium amansii. Rumput laut Gelidium amansii berasal dari perairan Negara Korea Selatan, yang diintroduksi ke perairan Indonesia untuk dikembangkan. Tujuan dari kegiatan ini adalah untuk melakukan uji pengembangan rumput laut Gelidium amansii dengan menggunakan metode apung sistem longline vertikal agar dibudidayakan di perairan Indonesia. Pertambahan bobot yang tinggi terjadi pada minggu ke-4 pengamatan yaitu antara 1 - 2 gram per titik sedangkan panjang thallus mencapai $7-9 \mathrm{~cm}$.

Ujicoba ini menggunakan metode apung sistem longline yang dimodifikasi yang dilakukan di perairan pantai selatan Pulau Lombok yaitu perairan Gerupuk Kecamatan Pujut Lombok Tengah Provinsi NTB. Kegiatan ini dilakukan pada bulan Agustus 2010 sampai dengan bulan Oktober 2010.
\end{abstract}

Kata kunci : Ujicoba, Rumput Laut Gelidium amansii, Longline vertikal, Pertumbuhan

\section{PENDAHULUAN}

\section{Latar Belakang}

Teknologi pengolahan rumput laut semakin meningkat seiring dengan tingginya kebutuhan manusia. Hasil olahan rumput laut selain dijadikan sebagai bahan makanan, obat-obatan, kosmetika dan lainnya, juga dapat dijadikan bahan baku bubur kertas (pulp) untuk pembuatan kertas. Jenis rumput laut yang dapat dijadikan sebagai raw material bubur kertas adalah jenis rumput laut alga merah (red algae) yang mempunyai kandungan serat (fiber) yang tinggi. Komoditas rumput laut yang dapat dijadikan sebagai bahan baku bubur kertas mempunyai dampak positif yang besar terhadap keselamatan lingkungan perairan dan lingkungan lahan atas (daratan). Rumput laut mempunyai potensi menyerap karbondioksida $\left(\mathrm{CO}_{2}\right.$ sink) dan juga dapat melepaskan oksigen $\left(\mathrm{O}_{2}\right)$ ke udara. Penggunaan kayu dari hutan sebagai bahan baku pulp dapat dikurangi, bahkan dapat tergantikan.

Pada saat ini, kurang dari 70 persen bahan baku untuk industri kertas berasal dari hutan alam. Indonesia sendiri memasok 2,5 persen dari kebutuhan kertas dunia yang mencapai 350 juta ton, dan pulp yang 200 juta ton per tahun. (www.beritaindonesia.com). Saat ini $90 \%$ bahan baku pulp di dunia 
berasal dari kayu, yang mencakup angka sekitar 170 juta ton per tahun. Sebanyak 640 juta meter kubik dikonsumsi setiap tahunnya, atau hampir sekitar $13 \%$ dari total kayu yang digunakan di seluruh dunia. Untuk memenuhi kebutuhan tersebut tanpa harus menebang hutan alam, maka dibutuhkan sekitar 10 juta hektar hutan tanaman yang harus ditanami setiap tahunnya. Inilah yang menjadikan pembuatan kertas dari bahan baku kayu berbenturan dengan kelestarian lingkungan hidup.

Pemanfaatan makro alga (rumput laut) merupakan salah satu alternatif sebagai penghasil bioethanol dan dapat menghasilkan bubur kertas (pulp). Sejak tiga tahun lalu, Prof. DR. Grevo Gerung bersama bersama Hack-Churl You (Pegasus International Inc) mengadakan penelitian. Mereka menemukan beberapa spesies rumput laut dan teknologi pengolahnya untuk menjadi pulp atau bubur kertas. Dari hasil riset, rumput laut dapat menghasilkan etanol dari fermentasi galaktosa. Grevo Gerung dan Hack-Churl You 2009 dalam penelitiannya menggunakan rumput laut red algae. Spesies yang dikembangkan yaitu Ptilophora $\mathrm{sp}$ dan Pteloclodia sp. Salah satu jenis rumput laut yang mempunyai serat tinggi dan baik adalah jenis Gelidium amansii. Rumput laut Gelidium amansii berasal dari perairan Negara Korea Selatan, yang diintroduksi ke perairan Indonesia untuk dikembangkan.

\section{Tujuan}

Tujuan dari kegiatan ini adalah untuk melakukan ujicoba budidaya rumput laut Gelidium amansii dengan menggunakan metode apung sistem longline vertikal agar dapat dibudidayakan di perairan Indonesia, sehingga menjadikannya sebagai komoditas diversifikasi selain rumput laut kotonii (Kappaphycus alvarezii).

\section{METODOLOGI}

\section{Waktu dan Tempat}

Waktu pelaksaanaan kegiatan dilakukan pada bulan Agustus - Oktober 2010 di perairan selatan pulau Lombok yaitu perairan Gerupuk Kecamatan Pujut Kabupaten Lombok Tengah Provinsi Nusa Tenggara Barat.

\section{Alat dan Bahan}

Alat-alat yang digunakan adalah peralatan kualitas air, timbangan eletrik dan alat tulis. Bahan yang digunakan adalah sarana budidaya metode apung sistem longline vertikal 1 (satu) unit (100 $\mathrm{m})$ dan rumput laut Gelidium amansii sebanyak $100 \mathrm{~kg}$.

\section{Metode}

Tahap kerja dalam kegiatan domestikasi ini adalah sebagai berikut penentuan lokasi, pembuataan sarana budidaya, penanaman, pemeliharaan dan kontroling, pengukuran kualitas perairan, pengukuran bobot dan panjang thallus.

Bobot thallus dihitung dengan rumus sederhana yaitu :
$\mathrm{W}=\mathrm{W} 1-\mathrm{Wo}$
(1) W= bobot akhir

Panjang thallus dihitung dengan rumus $P=P 1-P o \quad$ (2) $P=$ Panjang akhir

\section{HASIL DAN PEMBAHASAN}

\section{Penentuan Lokasi}

Habitat asli (wild type) rumput laut Gelidium amansii hidup melekat pada bebatuan atau karang di dasar perairan. Mereka hidup dan tumbuh pada musim panas dimana suhu perairan berada pada kisaran antara $20-26{ }^{\circ} \mathrm{C}$. Oleh karena itu, pola adaptasi yang dilakukan adalah 
dengan mengidentifikasi lokasi yang dapat meyerupai habitat aslinya. Adanya keterbatasan ketersediaan lahan budidaya dengan menggunakan lepas dasar atau lokasi pasang surut, sehingga diupayakan dilakukan budidaya dengan metode apung.

Penentuan lokasi ujicoba pengembangan budidaya rumput laut Gelidium amansii disesuaikan dengan kebiasaan hidupnya di alam, terutama kondisi perairan seperti suhu dan arus. Tidak semua perairan di Indonesia yang mempunyai karakteristik dengan perairan habitat rumput laut ini. Oleh karena itu diperlukan identifikasi yang akurat tentang lokasi ujicoba budidaya rumput laut ini. Adapun hasil identifikasi lokasi perairan yang menyerupai kehidupan habitat rumput laut ini adalah :

Tabel 1. Kondisi Perairan Lokasi Budidaya

\begin{tabular}{|l|l|c|}
\hline No & Parameter & Ukuran \\
\hline 1 & Suhu $\left({ }^{\circ} \mathrm{C}\right)$ & $20-29$ \\
\hline 2 & Salinitas $(\mathrm{ppt})$ & $32-33$ \\
\hline 3 & Kecerahan $(\%)$ & 100 \\
\hline 4 & Arus $(\mathrm{cm} / \mathrm{det})$ & $25-40$ \\
\hline 5 & $\mathrm{pH}$ & $7.7-8.2$ \\
\hline
\end{tabular}

(sumber : Rusman 2007).

Lokasi yang dipilih sebagai areal budidaya harus steril dari aktifitas lainnya seperti penangkapan dan budidaya laut lainnya, untuk mencegah terjadinya kontaminan terhadap rumput laut Gelidium amansii. Areal budidaya bersih dari predator seperti bulu babi (Diadema sitosum) dan ikan-ikan herbivora. Selain itu areal bersih dari tumbuhan laut lainnya yang dapat mengganggu kehidupan rumput laut Gelidium amansii seperti Ulva $\mathrm{sp}$, Gracillaria sp dan lumut benang.

\section{Konstruksi Sarana Budidaya}

Metode ujicoba budidaya yang digunakan adalah sistem longline yang dimodifikasi. Panjang longline yang digunakan adalah 100 meter. Spesifikasi bahan yang digunakan dalam metode lepas dasar ini adalah sebagai berikut:

Tabel 2. Spesifikasi Bahan Sistem Longline Vertikal.

\begin{tabular}{|l|l|c|c|}
\hline No & Spesifikasi & Bahan & Ukuran \\
\hline 1 & Tali utama & PE $12 \mathrm{~mm}$ & $110 \mathrm{~m}$ \\
\hline 2 & Tali gantungan ris vertikal & PE $10 \mathrm{~mm}$ & 2 meter \\
\hline 3 & Pemberat & Beton, besi & $100 \mathrm{~kg}$, jangkar \\
\hline 4 & Pelampung bola & Plastik & Diameter $35 \mathrm{~cm}$ \\
\hline 5 & Pocket mutiara & Waring persegi & $100 \times 100 \mathrm{~cm}$ \\
\hline
\end{tabular}

Pada prinsipnya konstruksi yang digunakan sama dengan konstruksi longline untuk budidaya mutiara atau rumput laut kotoni (Kappaphycus alvarezii). Adapun konstruksinya adalah sebagai berikut : 
Tabel 3. Spesifikasi Konstruksi Metode Lepas Dasar

\begin{tabular}{|l|l|c|}
\hline No & Spesifikasi & Ukuran \\
\hline 1 & Panjang tali utama & $100 \mathrm{~m}$ \\
\hline 2 & Jarak antar pelampung bola & $10 \mathrm{~m}$ \\
\hline 3 & Jarak antar gantungan & $5 \mathrm{~m}$ \\
\hline 4 & Kedalaman gantung & $1-2$ meter \\
\hline 5 & Panjang tali pemberat & 15 meter \\
\hline 8 & Jumlah titik tanam per pocket & 100 titik \\
\hline
\end{tabular}

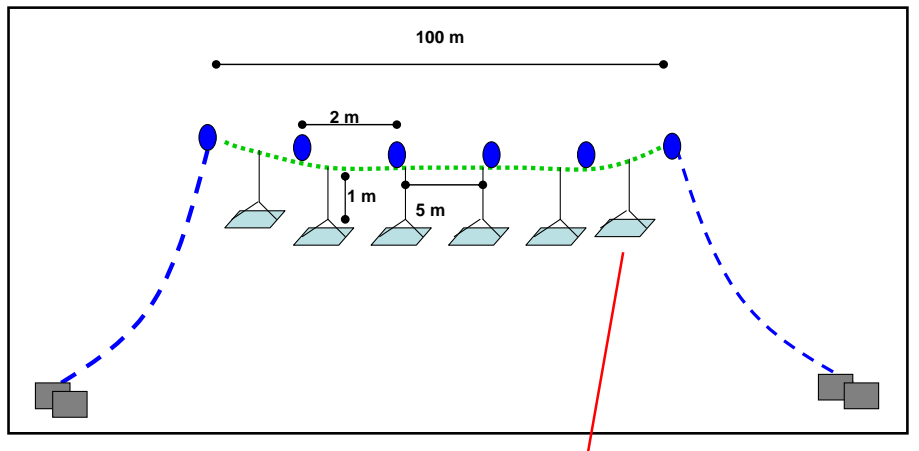

Gambar 1. Metode Longline Vertikal

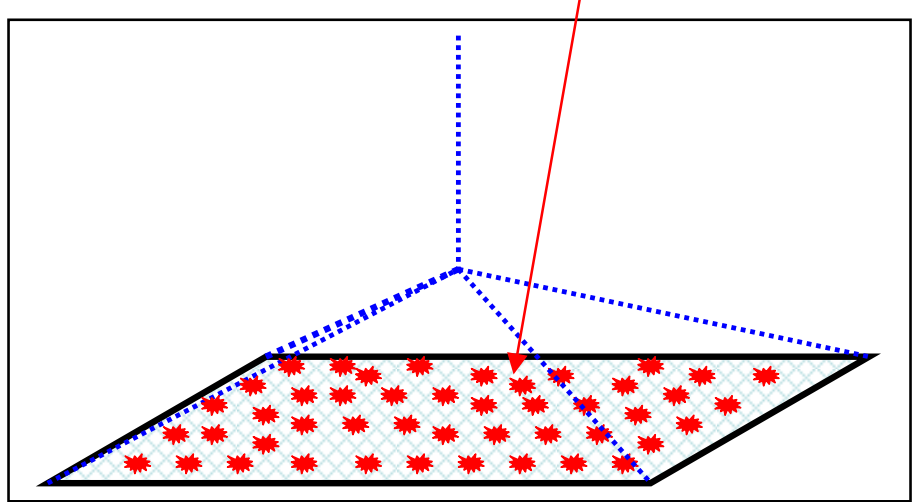

Gambar 2. Model Penanaman Rumput Laut pada "Pocket Mutiara"

\section{Penanaman bibit}

Bibit diikat pada pocket mutiara dengan menggunakan tali monofilament (tasik). Berat bibit yang ditanam dalam wadah pocket mutiara antara $20-30$ gram/titik dengan panjang thallus sekitar $5-7 \mathrm{~cm}$ (thallus terpanjang). Dalam satu pocket ukuran $1 \times 1$ meter terdapat bibit sebanyak 90 - 100 titik, sehingga dalam satu pocket terdapat 2000 gram atau $2 \mathrm{~kg}$ bibit rumput laut. Pocket yang berisi bibit digantung pada longline dengan kedalaman antara 1 - 2 meter dan jarak antar gantungan pocket 5 meter. Jumlah gantungan pocket dalam satu unit longline adalah 19 pocket, sehingga jumlah bibit yang ditanam adalah $38 \mathrm{~kg}$.

\section{Pemeliharaan}

Kontroling dilakukan setiap minggu untuk melihat kondisi pertumbuhan dan gangguan berupa penyakit dan predator serta organisme penempel seperti lumut benang dan sponge. Debu laut yang penempel dibersihkan dengan menggoyanggoyangkan pocket sampai pocket terlihat bersih, sedangkan sponge dan lumut dibersihkan dengan mencongkel atau membuangnya. 
Pertumbuhan

Hasil pengamatan dan
pengukuran tingkat hidup dan
pertumbuhan rumput laut jenis Gelidium
amansii, menunjukkan hasil yang masih rendah. Banyak faktor yang mempengaruhi tingkat hidup serta pertumbuhan rumput laut jenis Gelidium ini diantaranya kondisi perairan yang terjadi seperti suhu perairan dan kecepatan arus serta gangguan organisme penempel adalah :

\section{Suhu}

Suhu perairan mempunyai peran penting dalam kehidupan jenis alga merah Gelidium sp ini, karena habitat asal dari jenis adalah wilayah yang mempunyai iklim subtropis atau dingin. Gelidium sp dapat hidup dengan baik pada kisaran suhu $18-26{ }^{\circ} \mathrm{C}$, sedangkan suhu perairan di Indonesia sebagai iklim tropis antara $20-31^{\circ} \mathrm{C}$.

\section{Salinitas}

Salinitas di perairan laut hampir tidak ada perbedaan yang ekstrim kecuali salinitas disekitar sungai dan daerah limpasan air tawar yang besar. Umumnya salinitas air laut antara 32 - 33 ppt.

\section{Arus perairan}

Arus perairan mempunyai peran penting dalam pasokan nutrient. Selain itu, arus bersama dengan pasang surut mengaduk perairan sehingga sebaran suhu dalam kolom perairan merata (mixing). Arus juga membantu dalam membilas atau mencuci rumput laut dari kotoran atau tumbuhan penempel lainnya seperti lumut atau sponge.

4. Gangguan organisme penempel dan kotoran

Jenis rumput laut alga merah seperti Gelidium amansi Ptilophora sp mengeluarkan cairan sejenis lendir. Lendir inilah yang memacu organisme menempel dan kotoran seperti debu dan pasir serta sponge untuk melakukan penempelan pada rumput laut tersebut.

Tingkat pertumbuhan selama pengukuran yang dilakukan setiap minggu adalah sebagai berikut :

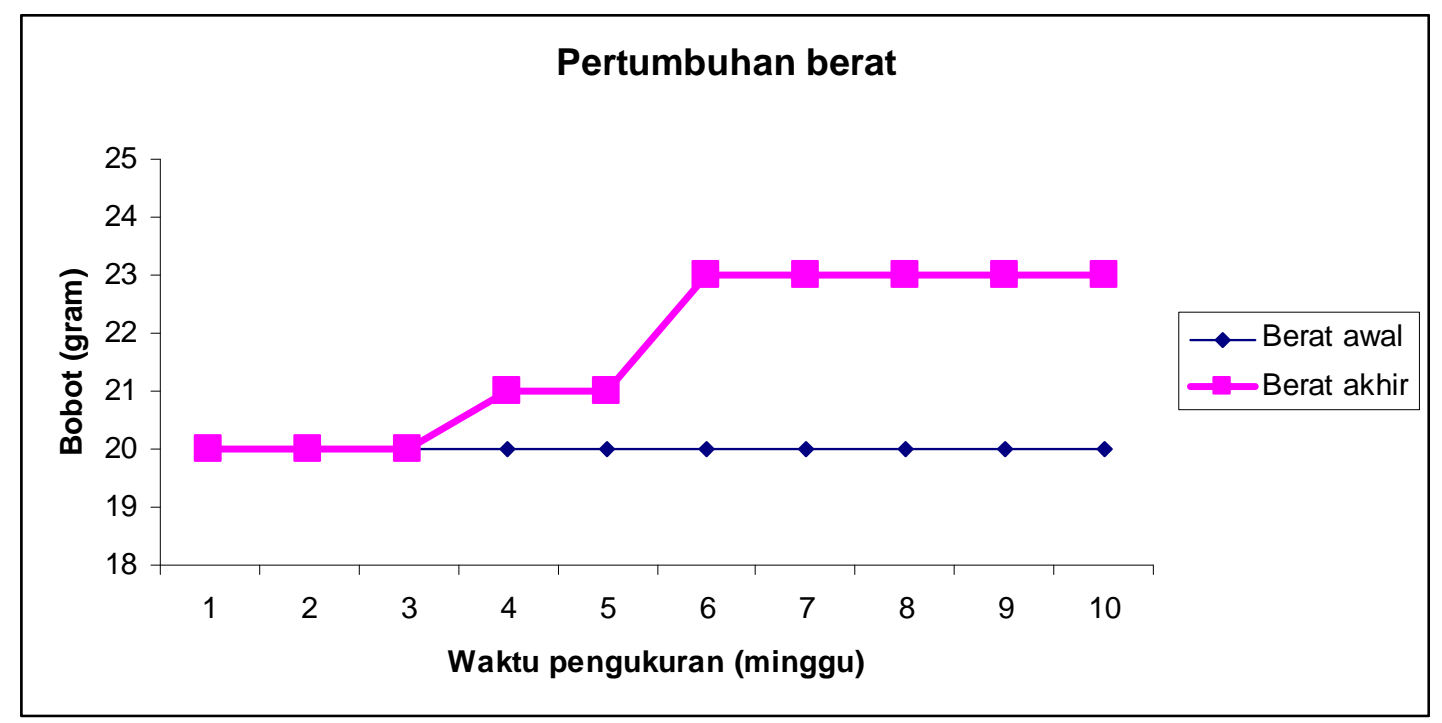

Gambar 3. Tingkat Pertambahan Bobot selama Masa Pemeliharaan 
Pertumbuhan rumput laut 65 - 70 hari. Pertambahan rata-rata Gelidium amansii ini sangat kecil. bobot terjadi pada minggu ke-4, kemudian Kemungkinan disebabkan oleh daya kembali stabil pada minggu ke-7 adaptasi yang lambat terhadap pemeliharaan. Beberapa diantara sampel lingkungan perairan dan metode yang juga mengalami kematian akibat tidak digunakan. Proses adaptasi rumput laut mampu beradaptasi. Kematian bibit ini terjadi karena adanya perubahan ditandai dengan perubahan pigmen kondisi hidup yaitu dari dasar perairan warna thallus menjadi berwarna hijau menuju ke permukaan perairan, sehingga kemudian berubah menjadi warna putih. pola kehidupan kemungkinan berubah.

Hasil pengamatan beberapa sample yang diuji, diperoleh rata-rata tingkat pertumbuhan antara 2 - 3 gram per siklusnya selama masa pemeliharaan
Tingkat kehidupan bibit yang ditanam selama masa pemeliharaan adalah $80 \%$ dari total bibit yang ditanam yaitu 1900 menjadi 1520 titik.

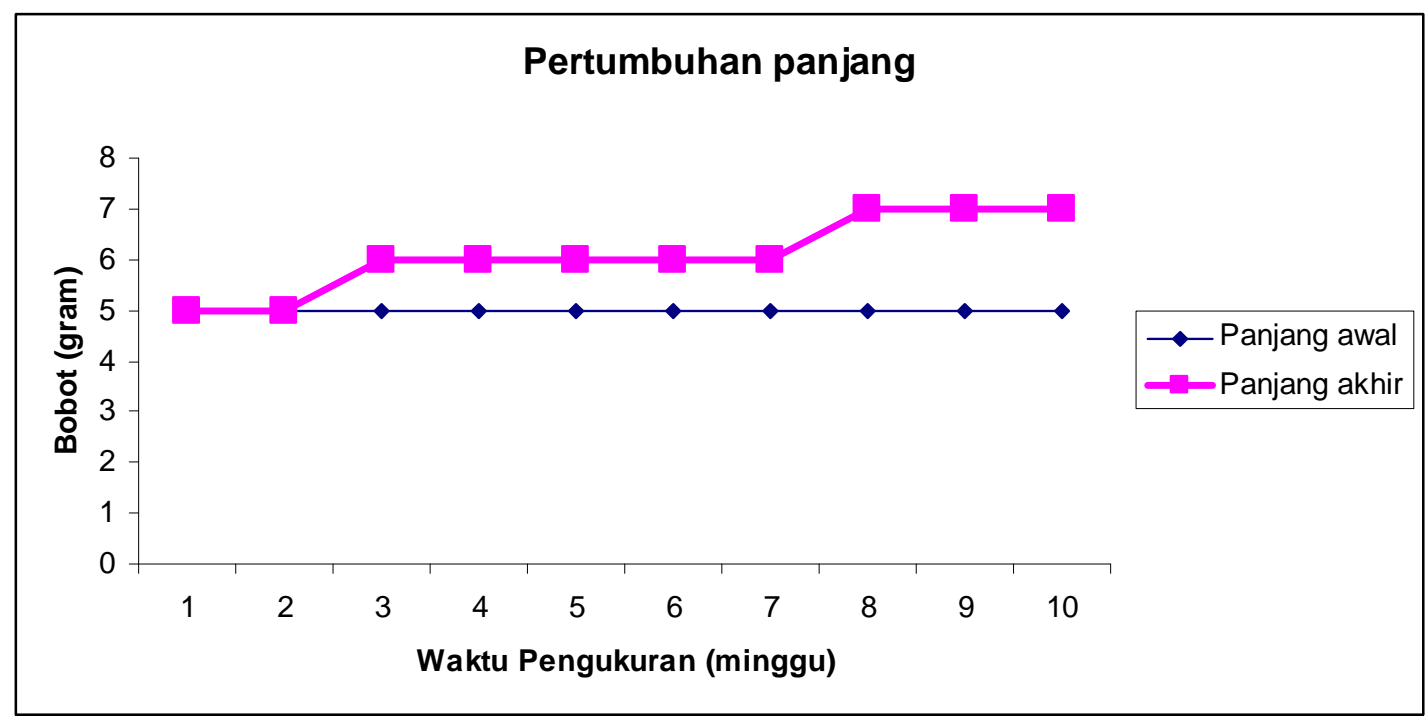

Gambar 4. Tingkat Pertambahan Panjang selama Masa Pemeliharaan

Panjang thallus hasil pengukuran pada thallus terpanjang diperoleh rata rata $7-9 \mathrm{~cm}$ dari panjang awal sekitar 5 - $7 \mathrm{~cm}$. Rendahnya capaian panjang yang diperoleh karena seringnya ujung thallus pemutihan (bleaching) dan patah. Kemungkinan disebabkan oleh serangan predator yaitu ikan-ikan kecil (herbivora) yang memakan thallus dan pergantian thallus. Walaupun panjang thallus menunjukkan peningkatan yang baik tetapi tidak sebanding dengan pertambahan bobot. Hal ini disebabkan karena rumput laut ini banyak mengalami perubahan morfologi yaitu diantaranya besar thallus yang makin kecil dan tidak elastis lagi.

Secara keseluruhan, rumput laut tersebut menunjukkan hasil yang baik dan dapat dibudidayakan di permukaan perairan, walaupun masih menunjukkan pertumbuhan kecil. Kemungkinan rumput laut ini dapat beradaptasi dan berkembang dengan baik pada keturunan selanjutnya. 
Pengukuran Kondisi Perairan

Hasil pengamatan

pengukuran kondisi perairan

budidaya selama proses pengembangan budidaya rumput laut

dan Gelidium amansii ini adalah sebagai

di areal berikut :

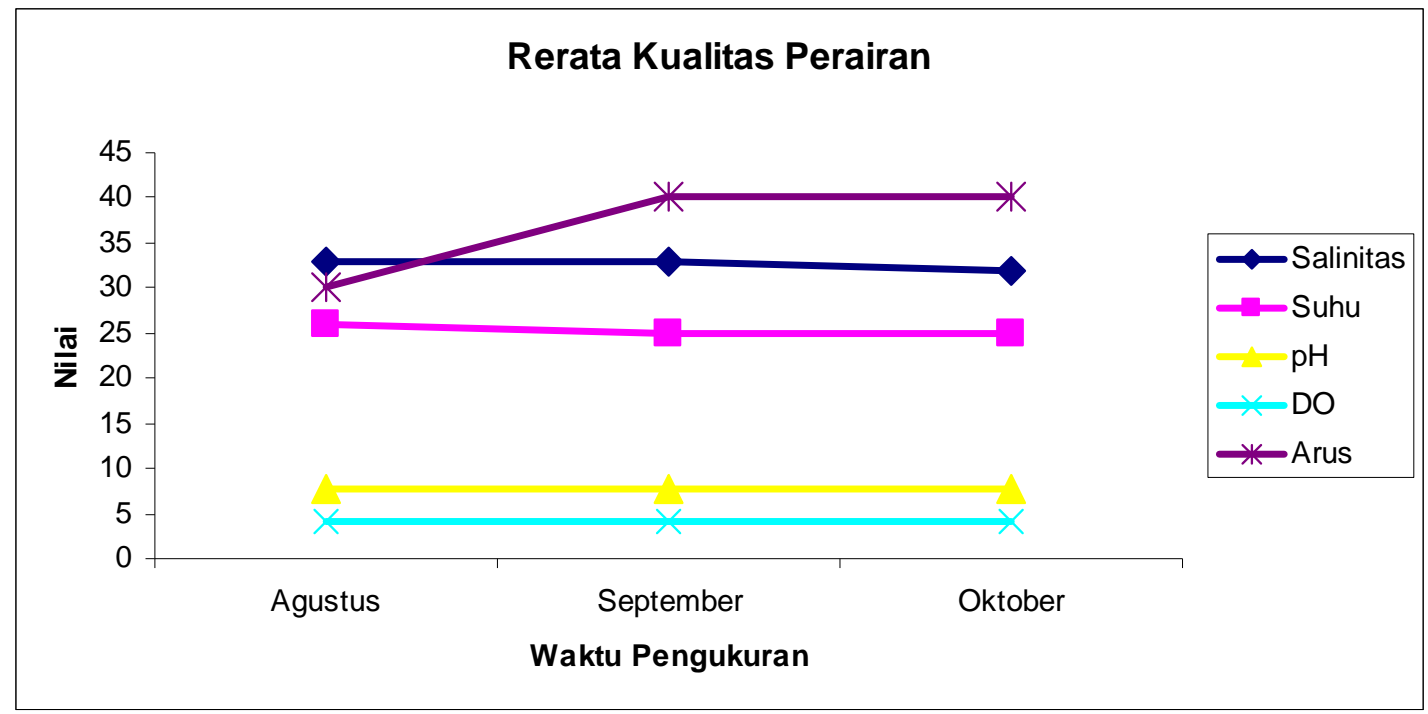

Gambar 5. Grafik Kualitas Perairan Teluk Gerupuk.

Kondisi kualitas air pada musim kemarau (bulan Agustus - Oktober) sangat mendukung kehidupan rumput laut Gelidium amansii, terutama parameter suhu perairan. Suhu perairan tercatat selama pengamatan berada pada ambang kehidupan rumput laut ini yaitu $25-26{ }^{\circ} \mathrm{C}$, dimana suhu optimunnya antara $24-26{ }^{\circ} \mathrm{C}$. Suhu perairan ini, tidak berbeda jauh dengan suhu perairan di perairan Korea (musim panas), dimana rumput laut ini berasal yaitu $18-26{ }^{\circ} \mathrm{C}$. Walaupun demikian, proses adaptasi terhadap suhu sangat lambat. $\mathrm{Hal}$ ini ditandai dengan banyaknya thallus yang memutih (bleaching) akibat perubahan suhu. Kecepatan arus yang terjadi di areal budidaya sangat baik bagi budidaya rumput laut ini yaitu rata-rata $30-40$ $\mathrm{cm} /$ det. Walaupun demikian, kondisi tersebut belum dapat mencegah terjadinya penempelan organisme penempel seperti sponge dan tumbuhan laut lainnya serta kotoran masih menempel pada rumput laut Gelidium amansii.

\section{Kendala dan Hambatan}

Beberapa kendala yang dihadapi dalam ujicoba pengembangan rumput laut jenis Gelidium sp ini adalah ;

1. Perubahan kondisi perairan

Perubahan kondisi perairan yang paling sering terjadi adalah suhu perairan. Perubahan ini karena adanya perbedaan suhu yang eksrim yang terjadi. Pada siang hari, penetrasi cahaya matahari sangat tinggi, menyebabkan suhu perairan kadang naik $1-2{ }^{\circ} \mathrm{C}$ menjadi 29 $-30{ }^{\circ} \mathrm{C}$. Fluktuasi suhu yang besar ini menyebabkan tingkat stressing yang tinggi dan dapat menyebabkan thallus menjadi putih (bleaching).

2. Penempelan benda asing

Rumput laut ini sangat mudah ditempeli oleh tumbuhan jenis lainnya seperti Ulva sp, Gracillaria sp, sponge dan tumbuhan laut lainnya. Walaupun 
tidak berbahaya tetapi dapat menghambat pertumbuhan, bahkan dapat menyebabkan kehilangan pigmen warna. Selain itu, butiran pasir dan debu laut sangat mudah menempel, sehingga menghalangi cahaya matari untuk mengenai thallusnya.

\section{Serangan Predator}

Predator yang sering menyerang rumput laut ini adalah ikan-ikan kecil, walaupun serangannya kecil tapi dapat merusak fisik rumput laut.

\section{KESIMPULAN DAN SARAN}

\section{Kesimpulan}

Kesimpulan yang dapat diambil dari kegiatan domestikasi rumput laut Gelidium amansii ini adalah :

1. Proses adaptasi yang sangat lambat, karena rumput laut ini sebagian thallusnya akan mengalami kerontokan, dan kemudian bertumbuh lagi.

2. Lingkungan perairan yang mempunyai pengaruh sangat besar adalah suhu perairan yaitu suhu yang baik bagi kehidupan rumput laut ini adalah 25 260 C. Arus perairan yang mendukung kehidupan rumput laut ini adalah $30-40 \mathrm{~cm} /$ det.

3. Pertambahan bobot yang tinggi terjadi pada minggu ke-4 pengamatan yaitu antara 1 - 2 gram per titik sedangkan panjang thallus mencapai $7-9 \mathrm{~cm}$.

4. Kendala yang sering muncul adalah penempelan organisme penempel seperti sponge, ulva sp, dan debu laut. Hal ini dapat merusak tanaman rumput laut.

\section{Saran}

Uji coba pengembangan rumput laut Gelidium amansii ini sebaiknya dilakukan selama setahun untuk memperoleh data yang time series sehingga dapat diperoleh data mengenai musim pertumbuhan optimun dan data kualitas perairan yang mendukung pertumbuhan rumput laut ini. Masih dibutuhkannya kondisi areal budidaya yang memadai untuk kehidupan rumput laut tersebut seperti kedalaman perairan.

\section{DAFTAR PUSTAKA}

Gerung, G.S. Hack Churl You. 2009. On the some species of Red Algae (Rhodophyta) From Indonesia: Producing Pulp and Bio-Ethanol. Paper.

Rusman, 2009. Laporan Introduksi dan Perkembangan Rumput Laut Gelidium amansii. Laporan. Lombok.

Rusman, 2008. Petunjuk Teknis Budidaya rumput Laut. Balai Budidaya Laut Lombok. Departemen Kelautan dan Perikanan. Buku. Lombok.

Rusman, 2007. Laporan Survay Lokasi untuk Budidaya Rumput Laut. Balai Budidaya Laut Lombok. Departemen Kelautan dan Perikanan. Laporan Lombok

Rusman, Grevo Gerung dan Bambang, 2010. Domestikasi Rumput Laut Gelidium amansii. Makalah. Lombok

You, H. C. dan Grevo Gerung. 2007. Pulp dan Paper, Made from Red Algae. Pegasus Int. Paper. Korea Selatan.

www.beritanindonesia.com., 2009. Penyebab Kerusakan Hutan di Indonesia. 2009.

www.kompas.com., 2009. Luas Hutan di Indonesia. 2009 